\title{
Flank bulge following subcostal percutaneous nephrolithotomy
}

This article was published in the following Dove Press journal:

Research and Reports in Urology

\author{
Joy Narayan Chakraborty' \\ Arup Deb² \\ 'Department of Urology, Apollo \\ Hospitals, Guwahati, India; \\ 2Department of Surgery, Apollo \\ Hospitals, Guwahati, India
}

\begin{abstract}
Loss of tone of the anterolateral abdominal wall muscles due to denervation injury is quite common after open renal surgery by lumbotomy incision. Although rare, flank bulge following percutaneous nephrolithotomy (PCNL) after supracostal approach has been reported in literature. But pseudohernia after PCNL with subcostal access has not been reported yet. In this case report, we present the rare complication of an abdominal wall bulge that occurred after PCNL with a subcostal access. The index case had been operated for a partial staghorn calculus with lower calyceal extension. PCNL with subcostal approach was used. Complete stone-free status was achieved with an uneventful recovery. During the first follow-up after 1 week, an unsightly, painless flank bulge was noticed, which continued to persist till 9 months of periodic follow-up. Keywords: flank bulge, percutaneous nephrolithotomy, subcostal access, pseudohernia
\end{abstract}

\section{Introduction}

Percutaneous nephrolithotomy (PCNL) is an established method of renal stone removal when the stone size is $>2 \mathrm{~cm}$. It is generally a safe and minimally invasive approach with low rate of clinically significant complications such as sepsis, severe hemorrhage with transfusion requirement and visceral injuries including pleural injury. Neurological complications are uncommon after PCNL and are usually associated with supracostal approach. ${ }^{1}$ Flank bulge after PCNL with subcostal access is unreported yet and is presumed to be due to injury to the main trunk of the subcostal nerve while doing initial puncture or tract formation.

\section{Case report}

A 47-year-old man was treated in February 2017 for a large partial staghorn calculus measuring $5.1 \times 3.8 \mathrm{~cm}$ and occupying the pelvis and lower calyx. PCNL was done in the prone position. Initial puncture was made in the subcostal region targeting the lower calyx. Tract dilatation was done with serial Teflon dilators (Cook). Double J ureteral stent and nephrostomy tube were placed after an uneventful surgery. The patient was discharged on the third postoperative day. During follow-up at 1 week, an unsightly, painless bulge was noticed at the left flank. An ultrasound was done, which failed to reveal any evidence of local collection, herniation or residual stone. Further follow-up at the second, third, sixth and ninth months did not show any sign of resolution (Figure 1).

\section{Discussion}

Flank bulge is a known complication of various retroperitoneal surgical procedures, which involves flank incisions. ${ }^{2,3}$ It has also been reported in neurosurgical and vascular 


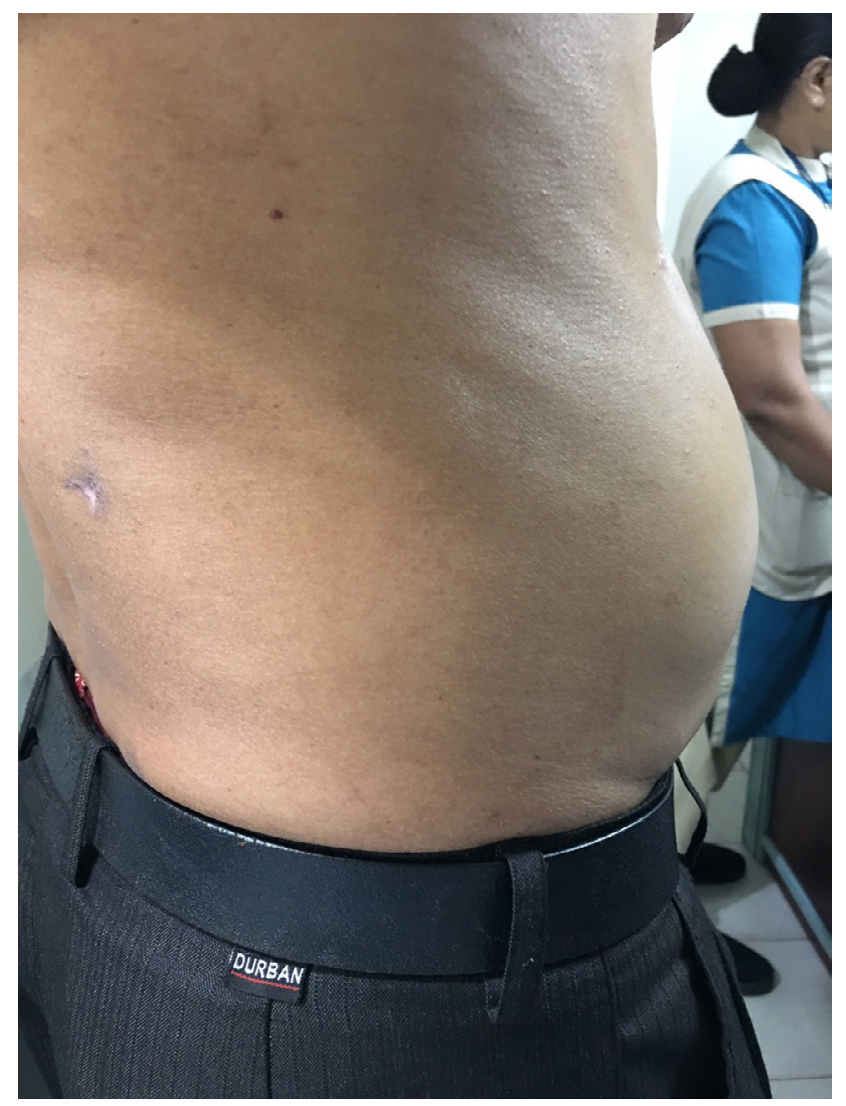

Figure I Left flank bulge after subcostal PCNL.

Abbreviation: PCNL, percutaneous nephrolithotomy.

procedures. ${ }^{4}$ Flank bulge after PCNL is rare, but reported in literature in PCNL with supracostal access. ${ }^{1}$ However, flank bulge following subcostal PCNL is unheard of and presumably, this is the first reported case.

The occurrence of postoperative abdominal flank bulge is most likely attributable to muscle denervation caused by injury to the T11 and T12 intercostal nerves. They are also called pseudohernias and are actually functional abdominal protrusions resembling hernias, but are not associated with evidence of muscular or fascial disruptions. ${ }^{5}$ Though clinically innocuous, it can be esthetically disturbing for patients.

According to Hardy, there is a significant variation in the "normal" anatomy of the intercostal nerves. ${ }^{6}$ The nerves do not commonly lie in the subcostal groove and, in fact, did so in only about $17 \%$ (classical subcostal position) of cadavers studied. In $73 \%$ of cases, it lies in the mid zone and in $10 \%$ of cases in the inferior supracostal position.

Alonso et al, in an anatomical study, stated that the subcostal nerve (T12) is the dominant nerve in both size and innervation for the anterolateral abdominal muscle. ${ }^{7}$ It is larger and has a wide field of distribution and more branches (eight on average) compared with the eleventh intercostal (T11) nerve (two on average). The subcostal nerve is often
(75\%) located up to $5 \mathrm{~cm}$ inferior to the 12 th rib in its initial course. The area of least concentration (safe zone) is located at approximately the midpoint between the lower edge of the 12th rib and the superior most aspect of iliac crest.

According to Fahim et al, the most significant contribution of the intercostal nerve to the anterolateral abdominal wall arises from $\mathrm{T} 11$ and T12. ${ }^{4}$ The authors, after cadaveric and electrophysiological study, classified the potential areas of nerve injury into three distinct anatomic zones: Zone I, segment of nerve along the body of the rib immediately proximal to the last few centimeters of the rib; Zone II, segment of intercostal nerve as it leaves the costal groove at the distal end of the floating rib and Zone III, segment that travels along the neurovascular plane between the internal oblique and the transversus abdominis muscle layer. An intercostal nerve that is not visualized can be directly damaged by passing a needle in this zone. Zone III injuries are unique in that they do not involve manipulation of the ribs as the intercostal nerve has left the relative shelter of the costal groove.

McAllister et al's study was all about supracostal access, where they suggested that access should be placed immediately lateral to the paraspinous muscles and in the lower half of the eleventh intercostal space, but at least $5 \mathrm{~mm}$ above the 12th rib, to reduce the potential for pain, bleeding and need for transfusion, while at the same time minimizing the risk of difficult insertion due to sheath catching on the 12th rib. ${ }^{8}$

According to Standring (Gray's Anatomy), the anterolateral wall of the abdomen is innervated by several branches of segmented spinal nerves. ${ }^{9}$ Hence, damage of a single spinal nerve branch is unlikely to produce loss of muscle tone severe enough to manifest as a flank bulge or pseudohernia. However, it can happen only when the main trunk of the subcostal nerve or several of its branches are injured. As the subcostal nerve often lies below the inferior border of the 12th rib (instead of subcostal groove), it is more liable to be injured by an access too close to the 12th rib, which may have happened in this case.

van der Graaf et al rightly said that minimizing damage to the intercostal nerve branches might prevent flank bulge, but at the same time, an accurate safe zone cannot be defined with $100 \%$ accuracy. This fact is more relevant in case of the subcostal nerve due to its more variable course. ${ }^{10}$

\section{Conclusion}

This is probably the first report of flank bulge as a complication after subcostal PCNL. The most plausible cause of this complication is presumed to be injury to the subcostal nerve during initial puncture and tract dilatation. The true incidence 
of this complication is unknown. It appears that, at present, there is no sure-shot method to avoid this.

\section{Ethical approval}

Ethical approval was taken from the hospital ethics committee for reporting this case.

\section{Consent}

A written informed consent was obtained from the patient for the anonymized information to be published in this article.

\section{Author contributions}

All authors contributed to data analysis, drafting or revising the article, gave final approval of the version to be published, and agree to be accountable for all aspects of the work.

\section{Disclosure}

The authors report no conflicts of interest in this work.

\section{References}

1. Lantz AG, Pace KT, Honey RJ. Flank bulge following supracostal percutaneous nephrolithotomy: a report of 2 cases. Can Urol Assoc J. 2013;7(7-8):E547.
2. Chatterjee S, Nam R, Fleshner N, Klotz L. Permanent flank bulge is a consequence of flank incision for radical nephrectomy in one half of patients. Urol Oncol. 2004;22(1):36-39.

3. Gardner GP, Josephs LG, Rosca M, Rich J, Woodson J, Menzoian JO. The retroperitoneal incision. An evaluation of postoperative flank 'bulge'. Arch Surg. 1994;129(7):753-756.

4. Fahim DK, Kim SD, Cho D, Lee S, Kim DH. Avoiding abdominal flank bulge after anterolateral approaches to the thoracolumbar spine: cadaveric study and electrophysiological investigation. $J$ Neurosurg Spine. 2011;15(5):532-540.

5. Butensky AM, Gruss LP, Gleit ZL. Flank pseudohernia following posterior rib fracture: a case report.JMedCaseRep. 2016;10(1): 273.

6. Hardy PA. Anatomical variation in the position of the proximal intercostal nerve. Br J Anaesth. 1988;61(3):338-339.

7. Alonso F, Graham R, Rustagi T, et al. The subcostal nerve during lateral approaches to the lumbar spine: an anatomical study with relevance for injury avoidance and postoperative complications such as abdominal wall hernia. World Neurosurg. 2017;104:669-673.

8. McAllister M, Lim K, Torrey R, Chenoweth J, Barker B, Baldwin DD. Intercostal vessels and nerves are at risk for injury during supracostal percutaneous nephrostolithotomy. $J$ Urol. 2011;185(1):329-334.

9. Standring S. Abdomen and Pelvis, Gray's Anatomy: The Anatomical Basis of Clinical Practice. 41st ed. New York, NY: Elsevier Health Sciences; 2015.

10. van der Graaf T, Verhagen PC, Kerver AL, Kleinrensink GJ. Surgical anatomy of the 10th and 11th intercostal, and subcostal nerves: prevention of damage during lumbotomy. J Urol. 2011;186(2):579-583.
Research and Reports in Urology

\section{Publish your work in this journal}

Research and Reports in Urology is an international, peer-reviewed, open access journal publishing original research, reports, editorials, reviews and commentaries on all aspects of adult and pediatric urology in the clinic and laboratory including the following topics: Pathology, pathophysiology of urological disease; Investigation and treatment of

\section{Dovepress}

urological disease; Pharmacology of drugs used for the treatment of urological disease. The manuscript management system is completely online and includes a very quick and fair peer-review system, which is all easy to use. Visit http://www.dovepress.com/testimonials.php to read real quotes from published authors. 